\title{
Universidade corporativa: estudo de caso da UniCopel quanto a percepção dos colaboradores lotados em três unidades organizacionais da região sudoeste do Estado do Paraná
}

\section{Corporate University: UniCopel case study on perception of employees placed in three organizational units of the southwest region of the state of Paraná}

\author{
Sandra Martins Moreira \\ Universidade Tecnológica Federal do Paraná - UTFPR - Ponta Grossa - Brasil \\ sandrammoreira77@gmail.com \\ Anderson Helfenstein \\ União de Ensino do Sudoeste do Paraná - UNISEP - Dois Vizinhos - Brasil \\ anderson.helfenstein@copel.com \\ Carlos Rogério Rodrigues da Silva \\ União de Ensino do Sudoeste do Paraná - UNISEP - Dois Vizinhos - Brasil \\ crrsilva@msn.com \\ Luiz Alberto Pilatti \\ Universidade Tecnológica Federal do Paraná - UTFPR - Ponta Grossa - Brasil \\ lapilatti@utfpr.edu.br
}

\begin{abstract}
Resumo
Educação Corporativa é a maneira mais estratégica e coerente de qualificar os profissionais atualmente. O processo de educar no trabalho deixou de ser utopia para se tornar a maneira mais dinâmica e eficaz de desenvolvimento profissional para trazer competitividade para a organização. Através da Universidade Corporativa, ferramenta que desenvolve este trabalho, a Companhia Paranaense de Energia -Copel criou a Universidade Corporativa da Copel-UniCopel, centralizando nela as atividades de treinamento e desenvolvimento do seu quadro de pessoal espalhados em dez Estados brasileiros e todo o interior do Paraná. Devido as dimensões da empresa, a maneira encontrada para padronizar os treinamentos foi a plataforma de ensino a distância $\mathrm{EaD}$, sendo fundamental para lapidação dos processos, realizar pesquisas como o presente trabalho que tem como objetivo avaliar as práticas da UniCopel na percepção de colaboradores lotados no interior do Paraná, mais precisamente na Região Sudoeste do estado (Dois Vizinhos, Realeza e Francisco Beltrão), por meio de questionário. O resultado obtido deixa claro a importância da UniCopel para a empresa, pois auxilia no surgimento de novas lideranças e motiva os trabalhadores a desenvolver-se em seu local de trabalho, bem como deixa explicito as oportunidades de melhorias a serem adotadas como a melhor performance da plataforma $\mathrm{EaD}$ e um calendário de treinamentos previamente definido.
\end{abstract}


Palavras-chave: educação corporativa, desenvolvimento profissional, universidade corporativa.

\begin{abstract}
Corporate Education is the most strategic and consistent way to qualify professionals today. The process of educating at work is no longer a utopia to become the most dynamic and effective way of professional development to bring competitiveness to the organization. Through the Corporate University, a tool that develops this work, the Companhia Paranaense de Energia - Copel created the Corporate University of Copel UniCopel, centralizing in it the training and development activities of its personnel in ten Brazilian states and the entire interior of the Paraná. Due to the size of the company, the way to standardize the training was the EaD distance learning platform, being fundamental which aims to evaluate the practices of UniCopel in the perception of employees crowded in the interior of Paraná, more precisely in the Southwest Region of the state (Dois Vizinhos, Realeza and Francisco Beltrão), through a questionnaire. The result obtained makes clear the importance of UniCopel to the company, as it assists in the emergence of new leaders and motivates the workers to develop in their workplace, as well as makes explicit the opportunities for improvements to be adopted as the best performance of the EAD platform and a pre-defined training calendar.
\end{abstract}

Keywords: corporate education, professional development, corporate university.

\title{
1. Introdução
}

A exigência cada vez maior por qualidade e produtividade que o mercado exerce nas grandes corporações, principalmente em um cenário atual de crise política e econômica que a sociedade brasileira enfrenta, somada ao desejo constante dos profissionais por aperfeiçoamento e crescimento em sua carreira, vem tornando cada vez mais necessário o desenvolvimento da educação corporativa (EC). Partindo deste princípio, Vieira (2012), descreve a EC como a oportunidade dada ao colaborador de aprender possibilitando a ele novas competências e atitudes, tornando propício o desenvolvimento pessoal e profissional e adaptando-o ao mercado de trabalho.

No entanto, Cruz (2010) acompanhando a visão de Bianchetti (2005), refutam este conceito e descrevem a EC como sendo de interesse apenas capitalista, já que as empresas estão buscando cada vez mais em escolas técnicas profissionalizantes potenciais colaboradores, inclusive trazendo para dentro das organizações este modelo de aprendizagem.

Neste contexto, Carvalho (2010), questiona se os treinamentos padronizados seriam capazes de suprir as necessidades crescentes das empresas em alinhar seus objetivos com seu capital intelectual, principalmente nas organizações que precisam da inovação. Seguindo o raciocínio de Meister (1999) e Carvalho (2010) ainda destaca que esta demanda vem tornando cada vez mais relevante o papel da Universidade Corporativa (UC), que na prática adapta os modelos de aprendizagem aos objetivos que a empresa possui.

Eboli (2004), destaca que os conceitos de Universidade e Educação Corporativa são muito próximos, sendo inclusive abordados em vários trabalhos acadêmicos como sinônimos, porém enfatiza que a EC é uma prática de desenvolvimento de pessoas que busca contratar, avaliar e remunerar de acordo com a gestão por competências, utilizando a Universidade Corporativa como ferramenta prática deste processo.

Compartilhando desta visão, Brandão (2006), descreve a UC como uma relevante evolução nos métodos para a gestão de pessoas por se tratar de um misto entre educação formal e desenvolvimento profissional. Porém salienta-se que há ganhos tanto 
para colaborador como para o empregador, e que apesar de a UC ser diretamente ligada aos objetivos da organização e que busca através de métodos de aprendizagem alavancar os resultados dos colaboradores, o colaborador tem como contrapartida a oportunidade de receber em seu local de trabalho, treinamento e qualificação profissional que talvez não conseguiria fora da empresa.

No Brasil, as Universidades Corporativas começaram a ganhar força na década de 1990 devido a pressão em organizações que lidam com o competitivo mercado internacional a desenvolver e qualificar sua mão de obra de maneira contínua. Desde então vem disseminando-se por todo o país em um movimento talvez sem precedentes para qualificação profissional (EBOLI, 2004).

Neste cenário, com os desafios impostos no setor elétrico brasileiro, associados a rigorosa legislação vigente imposta pelo seu órgão regulador, está inserida a Copel Companhia Paranaense de Energia, que em 2012 criou a UniCopel, Universidade Corporativa da Copel, com o papel fundamental de definir políticas e diretrizes de EC e treinamento e desenvolvimento de pessoas (T\&D), bem como coordenar tais atividades no âmbito da Copel (Holding) e suas subsidiárias integrais em todos os postos de trabalho espalhados pelo Paraná e demais Estados em que atua. Desta forma, o objetivo do trabalho é avaliar as práticas da UniCopel na percepção de colaboradores lotados no interior do Paraná, mais precisamente em sua Região Sudoeste do estado (Dois Vizinhos, Realeza e Francisco Beltrão), por meio de um questionário.

\section{Referencial teórico}

Com a disseminação cada vez maior do conhecimento e informação por diferentes meios, a visão dos gestores quanto ao seu capital humano teve de ser ampliada, gerando uma mudança de postura nas organizações na forma como lidar e desenvolver o público interno (ESTEVES, 2015).

Enfatiza-se a falta de afinidade entre o discurso e a prática dos gestores quanto ao tema em diversas organizações, já que o processo de treinamento e desenvolvimento T\&D de pessoas passa por uma gestão menos mecanicista e mais inspiradora, mantendo o colaborador motivado a continuar desenvolvendo-se.

Para Vieira (2012), muitos destes gestores que não investem em desenvolvimento e treinamento de seu quadro funcional, justificam sua atitude com a dificuldade de mensurar o retorno para os desembolsos financeiros aplicados com a implementação e sua posterior manutenção, principalmente em empresas menores onde as restrições de investimentos são mais latentes. Destaca-se ainda que o inverso ocorre em empresas maiores onde 0 T\&D vem ganhando cada vez mais destaque com a educação corporativa.

O termo Educação Corporativa - EC surgiu na década de 1950, quando a General Eletric criou a Crotonville (MEISTER, 1999). Cruz (2010), discorre sobre a visão de Meister (1999) em que a origem da EC se deu pela competitividade das grandes corporações americanas em tornarem-se líderes de seus segmentos no mercado global, lançando a educação corporativa como forma de obter vantagem competitiva.

Ainda de acordo com Meister (1999), com a contribuição de Vieira (2012), compreende-se EC como conjunto de métodos estruturados por determinada empresa, a fim de estabelecer a educação contínua e qualificação profissional. Acredita-se que após o seu amadurecimento, a EC pode atingir níveis estratégicos de desenvolvimento humano, alinhando desta forma o trabalhador com objetivos da empresa.

Entretanto Bianchetti (2005), relaciona o desenvolvimento da EC com os descompassos que o mercado capitalista julga "tradicionais" nas modalidades de ensino fora da empresa, e que o seu exponencial aumento se deve as lacunas deixadas pelas instituições de ensino ao preparar o profissional para o mercado de trabalho. Ressalta-se 
que nos moldes atuais, ocorre a mercantilização da educação, indo de encontro com as prescrições que o Banco mundial elaborou para questões relacionadas ao ato de educar.

A EC baseia-se em uma perspectiva mais abrangente, discorre Vieira (2012), pois o maior desafio é o de estabelecer uma nova cultura em que a educação se faça presente em todas as formas de trabalho, independentemente do nível de hierarquia ou tamanho da organização. Realça-se que toda mudança cultural requer mudanças de atitudes daqueles que estão inseridos neste processo e que somente assim as verdadeiras ligações entre a EC com as estratégias organizacionais são entendidas.

Vianna (2004) sugere que ocorra a criação de um novo departamento dentro das organizações chamado de Universidade Corporativa, extinguindo o departamento de treinamento e desenvolvimento para que desta forma a EC comece a ser implantada com fluência na empresa sem que o foco da mesma seja perdido.

A Universidade Corporativa - UC, surgiu nos Estados Unidos, onde o mercado econômico é pioneiro em agir de maneira mais inovadora e competitiva, o que justifica a sua aplicabilidade ser mais mercadológica do que conceitual (BRANDÃO, 2006). O conceito de Meister (1999), descreve a UC como um Treinamento e Desenvolvimento (T\&D) moderno onde busca-se agregar o valor do conhecimento adquirido às atividades do cotidiano empresarial.

Ramos (2008) é taxativo ao afirmar que o surgimento e a grande evolução das UC's se devem as lacunas deixadas pelo sistema educacional tradicional, forçando as empresas a adaptar modelos de aprendizagem para sua atividade-fim e trazendo para si a responsabilidade de moldar a sua força de trabalho.

Eboli (2004), explica o funcionamento da UC a partir dos seguintes conceitos:

- Objetivo Principal: Estimular e adaptar competências de acordo com as particularidades do negócio da instituição;

- Foco do Aprendizado: é fundamental focar na cultura organizacional almejada, para que o repasse do aprendizado seja uniforme entre todos e não ressalte apenas habilidades individuais;

- Escopo: deve estar traçado de maneira estratégica, privilegiando as necessidades do negócio;

- Programas Educacionais: a fim de atender o objetivo principal, a ênfase dos programas educacionais deve ser em aflorar as competências de maneira crítica alinhando ao que a organização espera, desta forma contribui para solidificar a cultura organizacional.

- Público-Alvo: a educação corporativa deve ser inclusiva, por isso os colaboradores não são o único publico alvo. $O$ desenvolvimento de competências críticas deve ser expandido a familiares, clientes, fornecedores e até mesmo na comunidade.

- Local: a prioridade, principalmente em organizações com estabelecimentos em vários locais diferentes, é conceber uma plataforma virtual. Não se exclui a possibilidade de uma sede física, porém esta não é uma prioridade.

- Resultados Esperados: aumentar a competitividade da organização, fortalecimento da cultura organizacional e desenvolvimento de pessoas por competências e não apenas por habilidades individuais.

Eboli (2004) ainda complementa que o pioneirismo com a implantação das universidades corporativas, traz hoje imensa vantagem para estas empresas quanto a retenção e desenvolvimento de talentos, pois como qualquer projeto empresarial novo a ser implementado, a UC sempre terá suas práticas lapidadas de acordo com as necessidades da instituição.

\subsection{Empresa}


A Copel - Companhia Paranaense de energia, foi fundada em 1954 e atua no ramo de telecomunicações além da geração, transmissão e distribuição de energia elétrica tendo seus negócios espalhados por dez estados brasileiros.

Embora a empresa tivesse instituído ainda no ano de 1963 a área de treinamento e desenvolvimento de pessoas, segundo a empresa, foi apenas em 2012 que decidiu-se dinamizar e implantar novos conceitos educacionais com a criação da UniCopel, tendo esta a missão de otimizar recursos e tornar o processo de treinamento e desenvolvimento de pessoas (T\&D) mais completo, onde formou-se uma equipe pedagógica com a contratação de colaboradores com a missão específica de administrar a UniCopel.

Segundo a UniCopel, o seu papel fundamental é definir políticas e diretrizes de educação corporativa e T\&D, bem como coordenar tais atividades no âmbito da Copel Holding e suas subsidiárias integrais, atuando também como agente integrador entre as ações educacionais e os negócios estratégicos da empresa, buscando o desenvolvimento da gestão de pessoas, da cultura de valores, da ética e da gestão do conhecimento, conforme definido no planejamento estratégico da companhia.

As atividades desempenhadas pela UniCopel, vão desde a elaboração e coordenação dos cursos de formação, programas de integração de novos colaboradores e cursos de obrigação legal, passando por programas de educação corporativa, formação de lideranças, sustentabilidade, integridade e de capacitação de língua estrangeira, chegando a cursos de pós-graduação e preparação para aposentadoria. Os treinamentos são divididos entre obrigatórios e opcionais, sendo que a participação e aproveitamento fazem parte dos critérios para avanços na carreira individual.

Segundo a Copel, em 2017 a Companhia investiu $\mathrm{R} \$ 7,5$ milhões nos programas de T\&D, onde foram criados 3.470 eventos de treinamentos com 41.458 participações dos colaboradores, totalizando 467.410 horas-aula, com média de 54,23 horas-aula por colaborador. Soma-se a estes dados 119 participações em programas de longa duração como curso de idiomas e pós-graduação

Ainda que possua uma sede física em Curitiba-PR onde realiza treinamentos presenciais, a UniCopel promove a maioria de suas ações de treinamento através da plataforma de ensino a distância (EAD), justificado principalmente pelo alto número de unidades organizacionais da empresa espalhadas por todo o Estado do Paraná, além de colaboradores lotados em outros nove estados brasileiros.

\section{Metodologia}

A pesquisa se classifica, segundo Gil (2009), como exploratória com abordagem qualitativa e quantitativa adotando os procedimentos de pesquisa de campo, bibliográfica e documental pois trata-se de um levantamento de dados coletados de um grupo específico da empresa objeto deste estudo.

Com base na pesquisa bibliográfica e nas informações obtidas junto a organização, deu-se pela elaboração de um questionário, sendo este aplicado nas unidades de Dois Vizinhos, Realeza e Francisco Beltrão, no mês de fevereiro 2018. O questionário foi enviado a $100 \%$ dos colaboradores (sendo eles 29) lotados nestas cidades e que possuem função administrativa.

O retorno foi de 22 questionários, representando $75,86 \%$ do total de colaboradores. Não se obteve $100 \%$ de respostas devido ao período de férias dos colaboradores, afastamento médico entre outros motivos desconhecidos. Os dados foram tabulados e estratificados em tabelas com posterior análise expressos na discussão dos resultados. 


\section{Resultados e discussões}

Os 22 colaboradores que responderam a pesquisa desempenham as seguintes funções na empresa atualmente:

Tabela 1: Função exercida atualmente

\begin{tabular}{lcc}
\hline \multicolumn{1}{c}{ Função } & Quantidade & Percentual \\
\hline Gerencial / Supervisão & 03 & $13,63 \%$ \\
Técnica & 07 & $31,81 \%$ \\
Administrativa & 12 & $54,54 \%$ \\
\hline
\end{tabular}

Fonte: Autoria própria (2018)

O resultado apresentado na Tabela 1, aponta que a amostra corresponde a três participantes que desempenham cargo de liderança na empresa, respondendo desta forma por $13,63 \%$ do universo pesquisado.

A função técnica é aquela em que o colaborador trabalha em sua sede organizacional realizando rotinas administrativas, no entanto quando necessário deslocase ao campo para obter informações para conclusões de relatórios, orientar o pessoal operacional, etc. Esta função está representada por $31,81 \%$ dos colaboradores.

A função que mais tem participação no grupo pesquisado é a administrativa, que representa $54,54 \%$ do total. Nesta função estão incluídos colaboradores que trabalham exclusivamente na sua sede organizacional com rotinas administrativas, atendimento a clientes e suporte para as áreas operacionais.

A Tabela 2 apresenta o tempo de trabalho dos funcionários na empresa.

Tabela 2: Tempo de trabalho na Copel

\begin{tabular}{ccc}
\hline Tempo de trabalho & Quantidade & Percentual \\
\hline Até 5 anos & 01 & $4,54 \%$ \\
De 5 a 10 anos & 08 & $36,36 \%$ \\
De 10 a 15 anos & 04 & $18,18 \%$ \\
De 15 a 20 anos & 03 & $13,63 \%$ \\
Acima de 20 anos & 06 & $27,28 \%$ \\
\hline
\end{tabular}

Fonte: Autoria própria (2018)

Constata-se na Tabela 2, que há um significativo número de trabalhadores que presenciaram o surgimento e evolução da UniCopel (surgimento em 2012) nestes quase seis anos de sua existência, sendo que a maioria possui um tempo de empresa em uma faixa intermediária de cinco a dez anos, que representam $36,36 \%$ do total.

É relevante também o número de colaboradores com mais de 20 anos de casa, com $27,27 \%$ do total, que por consequência tem experiência maior com a evolução dos antigos métodos de T\&D para a Universidade Corporativa. Em contrapartida, apenas um colaborador possui menos de cinco anos de empresa.

Afim de verificar a periodicidade com que realizam treinamentos desenvolvidos pela UniCopel, indagou-se aos colaboradores quantos treinamentos realizaram nos últimos seis meses (Tabela 3)

Tabela 3: Número de treinamentos realizados nos últimos 6 meses

\begin{tabular}{ccc}
\hline Item & Quantidade & Percentual \\
\hline Não lembra de ter realizado algum treinamento & 03 & $13,63 \%$ \\
Realizou até 3 treinamentos & 14 & $63,63 \%$ \\
Realizou mais que 3 treinamentos. Quantos? & 05 & $22,72 \%$ \\
\hline
\end{tabular}

Fonte: Autoria própria (2018)

A pesquisa aponta que a maioria dos entrevistados, 63,63\%, realizou ao menos um treinamento nos últimos seis meses, porém $13,63 \%$ afirmam não lembrar de ter realizado 
algum evento da UniCopel no mesmo período. No outro extremo estão os colaboradores que fizeram mais de três treinamentos. No outro extremo estão os colaboradores que fizeram mais de três eventos, sendo que há colaboradores com até 8 treinamentos concluídos no período.

A pesquisa também buscou levantar a percepção do colaborador quanto a carga horária disponibilizada para os treinamentos, bem como o tempo em que o mesmo fica disponível na plataforma EaD para a sua realização, obtendo-se os resultados apresentados na Tabela 4.

Tabela 4: Opinião do colaborador quanto a carga horária e o tempo em que fica disponível o treinamento na plataforma EAD

\begin{tabular}{ccc}
\hline Item & Quantidade & Percentual \\
\hline Atendem plenamente as necessidades & 03 & $13,63 \%$ \\
Em sua maioria atendem as necessidades & 13 & $59,09 \%$ \\
Em sua maioria não atendem as & & \\
necessidades & 04 & $18,18 \%$ \\
Não atendem as necessidades & 02 & $9,09 \%$ \\
\hline
\end{tabular}

Fonte: Autoria própria (2018)

Constata-se pelos dados da Tabela 4, que 59,09\% dos entrevistados, julga em sua maioria adequada a carga horária e o tempo em que o treinamento fica disponível para a realização dos treinamentos, sendo que apenas 13,63\% dos colaboradores avaliaram que os treinamentos atendem plenamente as necessidades.

$\mathrm{Na}$ contramão destes, $18,18 \%$ responderam que em sua maioria a carga horária não está condizente com as suas necessidades, sendo que 9,09\% se mostrou totalmente insatisfeita neste quesito.

Segundo a UniCopel o tempo de disponibilidade para fazer o treinamento, bem como a carga horária é avaliada devido ao tamanho do conteúdo a ser repassado variando desde apenas um dia como até vários meses o tempo de disponibilidade do evento na plataforma $\mathrm{EaD}$, o que na média representou 54,23 horas/aula por colaborador em 2017.

A pesquisa buscou compreender o quanto os treinamentos oferecidos pela UniCopel agregam valor na sua rotina profissional em uma escala de zero a dez, sendo que zero seria o menor grau de valor agregado e dez o máximo, as respostas são apresentadas na Tabela 5.

Tabela 5: Valor que os treinamentos agregam na rotina profissional

\begin{tabular}{ccc}
\hline Grau de Valor & Quantidade & Percentual \\
\hline 0 & 1 & $4,54 \%$ \\
1 & 0 & $0 \%$ \\
2 & 1 & $4,54 \%$ \\
3 & 2 & $9,09 \%$ \\
4 & 1 & $4,54 \%$ \\
5 & 1 & $4,54 \%$ \\
6 & 3 & $13,63 \%$ \\
7 & 7 & $31,81 \%$ \\
8 & 4 & $18,18 \%$ \\
9 & 1 & $4,54 \%$ \\
10 & 1 & $4,54 \%$ \\
\hline
\end{tabular}

Fonte: Autoria própria (2018)

Observa-se na Tabela 5 que a maioria do público pesquisado, 59,07\% atribui uma avaliação de intermediária para a alta quanto ao valor que os treinamentos possuem em seu cotidiano profissional, sendo que destes, $31,81 \%$ avaliou como sete o seu grau de valor atribuído. Ressalta-se também que há opiniões distribuídas também nos dois opostos da tabela, tanto com zero quanto dez na escala de valor dos treinamentos. 
O aproveitamento dos colaboradores na plataforma virtual é diferente, tendo em vista as vantagens e desvantagens desta modalidade de aprendizado. Os colaboradores foram questionados o quanto estão satisfeitos com seu aproveitamento dos treinamentos na plataforma EaD, em que se obteve os resultados expressos na Tabela 6.

Tabela 6: Aproveitamento com os treinamentos disponibilizados na plataforma EaD

\begin{tabular}{|c|c|c|}
\hline Aproveitamento com o EaD & Quantidade & Percentual \\
\hline $\begin{array}{l}\text { Muito satisfatório devido a } \\
\text { comodidade de realizar em }\end{array}$ & 04 & $18,18 \%$ \\
\hline $\begin{array}{l}\text { seu próprio local de trabalho } \\
\text { Satisfatório pois é tão } \\
\text { eficiente quanto fosse } \\
\text { realizado presencialmente }\end{array}$ & 13 & $59,09 \%$ \\
\hline $\begin{array}{l}\text { Mediano, pois entendo que } \\
\text { certos treinamentos } \\
\text { realizados pela plataforma } \\
\text { virtual deveriam ser } \\
\text { ministrados presencialmente }\end{array}$ & 03 & $13,63 \%$ \\
\hline $\begin{array}{l}\text { Insatisfatório, já que a } \\
\text { metodologia do treinamento } \\
\text { a distância é incapaz de } \\
\text { trazer resultados práticos em } \\
\text { minha vida profissional }\end{array}$ & 02 & $9,09 \%$ \\
\hline
\end{tabular}

Fonte: Autoria própria (2018)

Observa-se que grande parte dos entrevistados, com 59,09\%, julgam satisfatório o aproveitamento que se obtém juntos aos treinamentos pelo método EaD, pois para estes a comodidade de realizar os treinamentos em seu local de trabalho, organizando os horários de acordo com suas tarefas é uma grande vantagem.

Destaca-se ainda que $18,18 \%$ do público entrevistado, se dizem muitos satisfeitos com a plataforma EaD e que os treinamentos aplicados presencialmente ou a distância se equivalem.

Por outro lado, $13,63 \%$ e $9,09 \%$ consideram mediano e insatisfatório respectivamente, alegando que certos treinamentos realizados a distância deveriam ser feitos presencialmente, e que até mesmo possuem séria dificuldade de lidar com treinamentos EaD pois esta metodologia é incapaz de trazer resultados práticos em sua rotina profissional.

A UniCopel oferece aos colaboradores da companhia treinamentos que não são de caráter obrigatório, podendo o colaborador acessar e realizar estes eventos conforme necessidade ou disponibilidade. A Tabela 7 apresenta os colaboradores que foram indagados sobre quais treinamentos fazem e se há interesse dos mesmos por aqueles que não são obrigados a fazer.

Tabela 7: Treinamentos que os colaboradores procuram fazer.

\begin{tabular}{ccc}
\hline Treinamentos Realizados & Quantidade & Percentual \\
\hline Apenas os obrigatórios & 10 & $45,45 \%$ \\
Primeiro os obrigatórios e posteriormente os que me interessam & 09 & $40,90 \%$ \\
Todos os disponíveis, inclusive em ambiente externo da empresa & 03 & $13,63 \%$ \\
\hline
\end{tabular}

Fonte: Autoria própria (2018)

$\mathrm{Na}$ Tabela 7, constatou-se que a maioria dos colaboradores fazem apenas os eventos considerados obrigatórios, representando $45,45 \%$ dos entrevistados, seja por falta de interesse ou até mesmo disponibilidade. Outra parcela significativa procura adequar suas atividades diárias para realizar os treinamentos obrigatórios e posteriormente aqueles que interessam. 
Com $13,63 \%$, há aqueles que se organizam para realizar todos os eventos EaD, pois a UniCopel permite acessar seu portal em ambiente externo da empresa para aqueles que se interessam.

Por fim, foi solicitado aos entrevistados que elencassem de maneira aberta pontos fortes e fracos que identificam nos treinamentos que a UniCopel disponibiliza, sendo os apontamentos mais citados mostrados no Quadro 1.

Quadro 1: Pontos fortes e fracos da UniCopel

\begin{tabular}{|c|c|}
\hline Pontos Fortes & Pontos Fracos \\
\hline Parcerias com empresas do ramo de educação & Falta de parcerias no interior do Estado \\
\hline Custos menores para empresa com treinamentos EaD & $\begin{array}{l}\text { Não há um cronograma definido, sempre é } \\
\text { necessário adequar-se com as atividades }\end{array}$ \\
\hline Didática e materiais de qualidade & 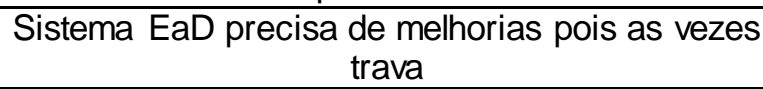 \\
\hline Cursos específicos para cada área de atuação & $\begin{array}{l}\text { Alguns treinamentos têm carga horária e tempo } \\
\text { de disponibilidade no sistema insuficientes }\end{array}$ \\
\hline Grade curricular excelente & Interação deficiente entre os participantes \\
\hline Comodidade devido ao sistema EaD & \multirow{5}{*}{$\begin{array}{l}\text { Treinamentos muito longos no EaD tornam-se } \\
\text { maçantes }\end{array}$} \\
\hline $\begin{array}{l}\text { Oportunidade de aprender e crescer } \\
\text { profissionalmente enquanto trabalha }\end{array}$ & \\
\hline $\begin{array}{c}\text { Instrutores que são especialistas no treinamento em } \\
\text { que aplicam }\end{array}$ & \\
\hline $\begin{array}{l}\text { Incentivo da gerência e da empresa para que se } \\
\text { realize os treinamentos }\end{array}$ & \\
\hline $\begin{array}{l}\text { Possibilidade de dar feedback sobre a experiência do } \\
\text { treinamento }\end{array}$ & \\
\hline
\end{tabular}

Fonte: Autoria própria (2018)

É possível identificar no Quadro 1 fatores que contribuem para a educação corporativa de qualidade, tais como, incentivo da gerência na realização dos treinamentos, feedback de como as atividades estão se desenvolvendo e parcerias com outras empresas do ramo de educação. É interessante também a consciência dos colaboradores ao apontar que a plataforma EaD traz custo menores para a empresa e também que os treinamentos disponibilizados não são mera burocracia, mas sim oportunidades de desenvolvimento pessoal e profissional.

No entanto, várias são as oportunidades de melhorias que a UniCopel pode levar em conta, como parcerias mais amplas disponibilizadas também em instituições do interior do Estado. Outros pontos fracos podem ser mais facilmente corrigidos, como o ajuste na plataforma EaD para que não trave, assim como elaboração de um cronograma de treinamentos a serem feitos, desta forma os colaboradores podem organizar-se previamente para realizar os eventos, inclusive quanto a férias.

\section{Conclusão}

Avaliar as percepções dos envolvidos em qualquer processo sempre é relevante para lapidar os métodos e práticas. Na Educação Corporativa - EC isto tem ainda mais importância, tendo em vista que um dos grandes objetivos das Universidades Corporativas - UC é receber o feedback positivo dos colaboradores.

Apesar da UniCopel estar caminhando para seis anos de vida, muitos são os pontos positivos que ela possui na visão dos colaboradores. Destaca-se o alto índice de valor agregado na rotina profissional que a UC promove entre os colaboradores e também a satisfação com os métodos de treinamento $\mathrm{EaD}$ que são oferecidos, respondendo por $31,81 \%$ e $59,09 \%$ dos colaboradores respectivamente. 
Releva-se, que muitas são as oportunidades de melhorias dos processos da UniCopel, como a falta de cronograma dos treinamentos que impedem uma organização prévia do colaborador e até mesmo da área em que ele está inserido, há ainda a questão de disponibilidade de parcerias com empresas do ramo de educação disponíveis apenas em cidades maiores, fazendo com que a opinião de colaboradores lotados em cidades menores, que são o objeto deste trabalho, seja de descontentamento com esta prática. Outra informação que chama a atenção é que $45,45 \%$ realizam apenas os eventos obrigatórios mesmo tendo outros treinamentos disponibilizados.

É de interesse da própria Copel os resultados de pesquisas de opiniões dos seus colaboradores. Observando os pontos fortes elencados pelos colaboradores percebe-se que a empresa e UC atuam em sintonia já que as gerências incentivam os colaboradores a realizar os eventos.

Enfim, pesquisas de opinião/percepção são extratos da realidade dos processos e métodos, sendo uma importante ferramenta para avaliar os pontos fortes e trabalhar na melhora dos pontos fracos, principalmente quando se discute educação corporativa, tema tão importante e estratégico para grandes empresas, como a Copel.

\section{Referências}

BIANCHETTI, L. Educação Corporativa, novos protagonistas e novos loci espaçotemporais de formação dos trabalhadores. 2005. Trabalho apresentado no Congresso da Universidade de Aveiro, Portugal, 2005.

BRANDÃO, G. R. Gestão de pessoas e as universidades corporativas: dois lados da mesma moeda. RAE - Revista de Administração de Empresas, v. 46, n. 2, p.22-33, 2006.

CARVALHO, A. P.; REIS, D. R.; MATOS, E. A. A.; CARVALHO, S. Vantagens na Implantação da Universidade Corporativa. Ciências Sociais Aplicadas em Revistas, v. 10, n. 18, p.113-125, 2010.

CRUZ, D. Educação corporativa: A proposta empresarial no discurso e na prática. Educação em Revista, v. 26, n. 2, p.317-357, 2010.

EBOLI, M. Educação Corporativa no Brasil: Da prática à Teoria, In EnANPAD, XXVII, 2004, Curitiba. Anais ... Curitiba, ANPAD, 2004.

ESTEVES, L. P. A Educação Corporativa e a Gestão do Conhecimento, Congresso Nacional de Excelência em Gestão, XI, 2015, Rio de Janeiro. Anais... Rio de Janeiro, FIRJAN, 2015.

GIL, A. C. Métodos e Técnicas de Pesquisa Social. São Paulo: Atlas, 2009.

MEISTER, J. C. Educação Corporativa. São Paulo: Makron Books, 1999.

RAMOS, G. S; SANTOS, A. F. T. Valer (vá ler?): formação de trabalhadores sob a ideologia do mercado na universidade corporativa da Vale. São Paulo, 2008.

VIANNA, M. A. Estratégia e Humanismo. Instituto MVC, 2004. Disponível http://www.institutomvc.com.br/ acesso em out-2017. 
VIEIRA, F. H. A.; FRANCISCO, A. C. Etapas da implementação da educação corporativa e seus impactos em empresas brasileiras: um estudo multicaso. Produção, v. 22, n. 2, p.296-308, 2012. 